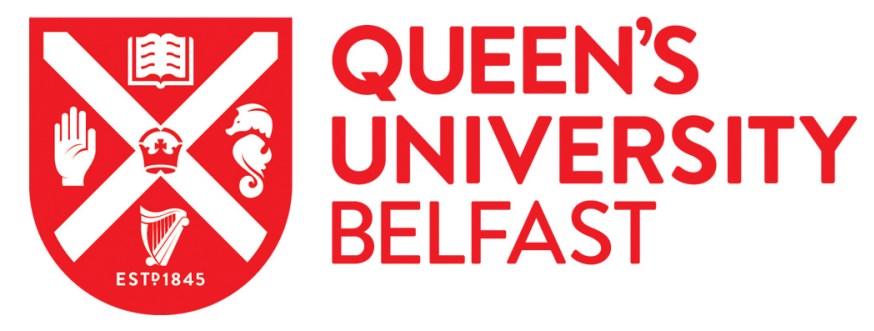

\title{
Having an Eye for Species Identification: Iris Colouration Is Diagnostic In Highly Variable Leaf Litter (Craugastor: Craugastoridae) Frogs
}

D'Souza, ML., Witt, JDS., Kolby, J., Clegg, J., Jankowski, A., Sólis, JM., Laking, A., McKeown, S., Galdamez, JR., Taylor, P., Radage, A., Green, S., Reid, N., \& Jocque, M. (2016). Having an Eye for Species Identification: Iris Colouration Is Diagnostic In Highly Variable Leaf Litter (Craugastor: Craugastoridae) Frogs. Entomology, Ornithology \& Herpetology: Current Research, 5(2). https://doi.org/10.4172/2161-0983.1000178

Published in:

Entomology, Ornithology \& Herpetology: Current Research

Document Version:

Publisher's PDF, also known as Version of record

Queen's University Belfast - Research Portal:

Link to publication record in Queen's University Belfast Research Portal

Publisher rights

(C) 2017 The Authors

This is an open access article published under a Creative Commons Attribution License (https://creativecommons.org/licenses/by/4.0/), which permits unrestricted use, distribution and reproduction in any medium, provided the author and source are cited.

\section{General rights}

Copyright for the publications made accessible via the Queen's University Belfast Research Portal is retained by the author(s) and / or other copyright owners and it is a condition of accessing these publications that users recognise and abide by the legal requirements associated with these rights.

Take down policy

The Research Portal is Queen's institutional repository that provides access to Queen's research output. Every effort has been made to ensure that content in the Research Portal does not infringe any person's rights, or applicable UK laws. If you discover content in the Research Portal that you believe breaches copyright or violates any law, please contact openaccess@qub.ac.uk. 


\title{
Having an Eye for Species Identification: Iris Colouration Is Diagnostic In Highly Variable Leaf Litter (Craugastor: Craugastoridae) Frogs

\author{
D'Souza ML ${ }^{1,2 *}$, Witt JDS ${ }^{2}$, Kolby $\mathrm{J}^{1}$, Clegg $\mathrm{J}^{1}$, Jankowski ${ }^{3}$, Solís $\mathrm{JM}^{1,4}$, Laking $\mathrm{A}^{1,5}$, McKeown $\mathrm{S}^{1}$, Galdamez $\mathrm{JR}^{1,4}$, Taylor $\mathrm{P}^{1}$, Radage $\mathrm{A}^{1}$,
} Green $\mathbf{S}^{1}$, Reid $\mathbf{N}^{1,6}$ and Jocque $\mathbf{M}^{1,7}$
}

${ }^{1}$ Operation Wallacea, Hope House, Old Bolingbroke, Lincolnshire, UK

${ }^{2}$ Department of Biology, University of Waterloo, 200 University Ave. West, Waterloo, ON, N2L 3G1, Canada

${ }^{3}$ Biozentrum Grindel \& Zoologisches Museum Section Animal Ecology and Conservation University of Hamburg, Martin-Luther-King Platz 3, 20146 Hamburg, Germany

${ }^{4}$ Facultad de Ciencias, Escuela de Biología, Universidad Nacional Autónoma de Honduras, Depto. de Francisco Morazán, Tegucigalpa, Honduras

${ }^{5}$ Department of Biology, Vrije Universiteit Brussel, Boulevard de la Plaine 2, 1050 Ixelles, Belgium

${ }^{6}$ School of Biological Sciences, Queen's University Belfast, Belfast, BT9 7BL, UK

${ }^{7}$ Royal Belgian Institute of Natural Sciences, Aquatic and Terrestrial Ecology (ATECO), Vautierstraat 29, 1000 Brussels, Belgium

\begin{abstract}
An important aspect of evaluating biodiversity in a region, starting a monitoring program or informing conservation management decisions is having a good understanding of the taxonomy of local species. However, identification to the species-level can be challenging. A combination of DNA-based and phenotypic character analysis can provide a preliminary species list and help identify diagnostic features for taxonomically difficult groups such as the Neotropical leaf litter frogs (Craugastor spp.). We used $16 \mathrm{~S}$ and $\mathrm{COI}$ marker sequences to assess the number of phylogenetic Craugastor species present in Cusuco National Park, Honduras. We conducted a linear discriminant analysis to determine if phenotypic characteristics could validate identified monophyletic species. Subsequently, we evaluated the efficacy of the Automatic Barcode Gap Discovery (ABGD) algorithm, a DNA sequence similarity-based tool, for species delineation within Neotropical amphibians. Phylogenetic analyses conducted on sequences derived from 194 specimens produced concordant results between both loci, with reciprocal monophyly of mitochondrial DNA haplotypes for all clades, revealing the presence of four Craugastor species: C. rostralis, C. chac, C. laticeps and C. c.f. charadra. Iris colouration was discovered to be a diagnostic character and the ABGD algorithm accurately identified all four monophyletic species within the phylogenetic and phenotypic analyses. A further three species have been reported from Cusuco National Park including C. milesi, C. laevissimus and C. coffeus. These species are more readily identifiable than the cryptic species we examined, but they have yet to be confirmed using molecular analyses. We demonstrate that the use of molecular tools, in conjunction with the post hoc evaluation of phenotypic variation, can aid with the delineation of cryptic biological diversity and with the discovery of key diagnostic features for accurate species recognition in the field.
\end{abstract}

Keywords: Iris; Species; Phylogenetic; Amphibian; Phenotypic

\section{Introduction}

An accurate assessment of species richness is a critical first step toward informed conservation and management decisions at a regional level. Species identification can be achieved with the use of morphological or molecular approaches, or better still, a combination thereof [1-4].

Molecular tools are highly valuable in the discovery and identification of species, particularly when traditional taxonomic identification is difficult to apply, such as cases of cryptic diversity $[5,6]$. DNA sequence-based identification commonly employs a comparison of unknown individuals with a reference sequence library, but this has limited use in the study of lesser-known taxa where a reference library may not be established [7]. A range of tools have been developed to effectively group the sequences derived from individuals into species clusters without subjective thresholds [8-10]. The Automatic Barcode Gap Discovery (ABGD) algorithm has been a particularly useful tool because it allows multiple thresholds to be evaluated as opposed to a single standard limit [11]. It statistically infers the potential threshold value from a set of input sequences, partitions the data based on that threshold, and then recursively applies the same procedure to the newly obtained groups of sequences. ABGD has previously been successful in species demarcation and cryptic species identification, particularly within taxonomically difficult amphibian groups $[12,13]$.

Despite the benefits of such approaches in the lab, it remains necessary to have a reliable identification toolkit in the field. Species identification in the field must rely on phenotypic characteristics and, in some taxonomic groups, is unreliable especially when performed by multiple inexperienced surveyors. Advice on species identification from a taxonomic expert is often unavailable, particularly within reasonable timeframes. Additionally many diagnostic features often require microscopy or detailed examination and dissection of a specimen which is clearly inappropriate in the field. The incorporation of reliable yet manageable diagnostic phenotypic characteristics into molecularly classified groups is an important final step in the demarcation of cryptic species yet it is often overlooked.

This study tests the efficacy of the ABGD algorithm in conjunction with a phenotypic character analysis for species demarcation within the taxonomically difficult amphibian genus Craugastor. This diverse genus of leaf litter frogs, endemic to the Neotropics, include 113 species [14] that reproduce terrestrially where eggs hatch directly into

*Corresponding author: Michelle D'Souza, Biodiversity Institute of Ontario University of Guelph, 50 Stone Road East, Guelph, ON, Canada N1G 2W1, Tel: 226-978-1369; E-mail: mdsouza@uoguelph.ca

Received February 08, 2016; Accepted May 20, 2016; Published May 25, 2016

Citation: D'Souza ML, Witt JDS, Kolby J, Clegg J, Jankowski A, et al. (2016) Having an Eye for Species Identification: Iris Colouration Is Diagnostic In Highly Variable Leaf Litter (Craugastor: Craugastoridae) Frogs. Entomol Ornithol Herpetol 5: 178. doi:10.4172/2161-0983.1000178

Copyright: (c) 2016 D'Souza ML, et al. This is an open-access article distributed under the terms of the Creative Commons Attribution License, which permits unrestricted use, distribution, and reproduction in any medium, provided the original author and source are credited. 
Citation: D'Souza ML, Witt JDS, Kolby J, Clegg J, Jankowski A, et al. (2016) Having an Eye for Species Identification: Iris Colouration Is Diagnostic In Highly Variable Leaf Litter (Craugastor: Craugastoridae) Frogs. Entomol Ornithol Herpetol 5: 178. doi:10.4172/2161-0983.1000178

Page 2 of 7

small froglets bypassing the free-living tadpole stage. The taxonomy of species within this genus has been principally based on morphological characteristics but Craugastor species are known to show extreme phenotypic variability within populations [15], and they often lack distinct diagnostic features that can facilitate species recognition in the field. As taxonomic assignments within Craugastor are frequently accompanied by disagreement among experts, genetic characterization has become an indispensable tool for species determination within this group [16].

Many Craugastor species are at risk due to habitat destruction or modification, emerging pathogens (for example, the chytrid fungus Batrachochytrium dendrobatidis) or climate change [17]. Leaf litter frogs inhabit lowland humid rainforest but can also occur at high altitude in fragmented and isolated patches of cloud forest. Cusuco National Park in north-western Honduras (Figure 1) is currently listed as the 25th most irreplaceable site (out of 173,000 protected sites) for amphibian biodiversity on Earth [18]. A total of seven Craugastor species have been recorded in Cusuco National Park (Table 1) on the basis of morphology over nine years (2006-2015) of annual field surveys (Operation Wallacea Ltd., unpublished data). Some species can be reliably recognized, such as Miles' Robber Frog (Craugastor milesi), but most species, including the common Craugastor rostralis and Craugastor chac, are difficult to identify in the field and observational records are highly unreliable due to a lack of key diagnostic features.

This study aims to i) confirm the morphologically identified Craugastor species present in Cusuco National Park using molecular techniques, ii) find reliable and easy-to-use phenotypic characteristics for accurate recognition of species in the field, and finally iii) test whether sequence similarity-based approaches, such as the ABGD algorithm can accurately identify monophyletic species groups.

\section{Material and Methods}

\section{Data collection}

Cusuco National Park (23,440 ha) consists of montane cloud forest and is part of a larger protected forest region that includes the Merendón Reserve range with an elevation gradient from $30 \mathrm{~m}$ to 2,240 $\mathrm{m}$ above sea level. Craugastor sampling was carried out by Operation Wallacea Ltd. during seasonal surveys for biodiversity in selected sites across the national park. Specimens were captured during visual encounter surveys of standardized transects at six sites over a three year period during 2011 to 2013 between the months June to August (Figure 1). Tissue samples from all Craugastor encountered on transects were collected resulting in a total of 194 specimens sampled from Cusuco National Park (Table S1).

All sampling was non-lethal and individuals were released within 15 minutes of capture, complying with research ethics codes of conduct (CCAC guidelines). Buccal swabs or toe clips were collected and stored in $95 \%$ ethanol. Specimens were measured and photographed when possible resulting in $95(49 \%)$ and 138 (71\%) specimens with good quality image data (Table S2) and a complete set of morphological measurements (Table S3) respectively. Photographs included a dorsolateral and ventral shot of the complete animal and a lateral close up of the head centred on the eye. Using dial callipers, eight body measurements were taken to the nearest $0.1 \mathrm{~mm}$ following Duellman [19] , Lynch and Duellman [20], specifically: distance from snout to vent, horizontal tympanum diameter, eye/tympanum diameter ratio, head width at its broadest point, head length from posterior end of tympanum to tip of snout, the snout length measured between anterior corner of eye and posterior nostril, hind leg length, foot length from the proximal edge of the heel to the tip of toe IV ( Figure S1). Additionally, the body weight of each specimen was attained using a Pesola spring scale $(10,20$ or $60 \mathrm{~g})$ to the nearest $0.1 \mathrm{~g}$. The following characteristics

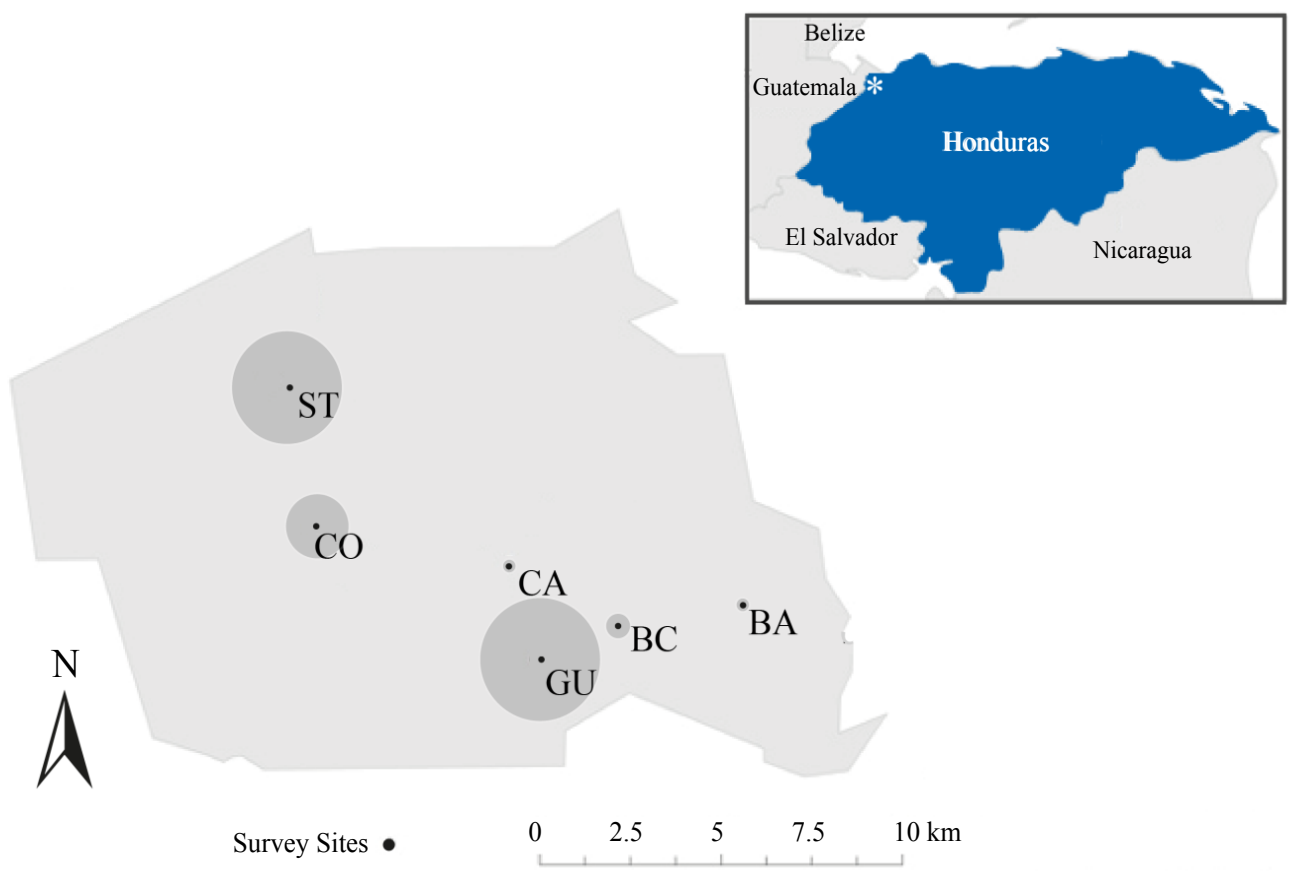

Figure 1: Map of Honduras with white star indicating Cusuco National Park (top-right) and map of Cusuco National Park displaying six survey sites $(\bullet)$ with grey circles proportional to number of specimens collected at each site (bottom-left). Collection sites included Buenos Aires (BA), Base Camp (BC), Cantiles (CA), Cortecito (CO), Guanales (GU), and Santo Tomas (ST). 


\begin{tabular}{|c|c|c|}
\hline IUCN category & Latin name & Reference \\
\hline Near threatened (NT) & Craugastor chac & {$[21]$} \\
\hline & Craugastor laticeps & {$[40]$} \\
\hline & Craugastor rostralis & {$[41]$} \\
\hline Endangered (EN) & Craugastor charadra & {$[42]$} \\
\hline & Craugastor laevissimus & {$[41]$} \\
\hline Critically endangered (CR) & Craugastor coffeus & {$[43]$} \\
\hline & Craugastor milesi & {$[44]$} \\
\hline
\end{tabular}

Table 1: Craugastor species found in cusuco national park and their current IUCN categorization.

were recorded from each photograph: colour of the ventral surface of thighs including yellow, red, orange or uncolored; the presence or absence of a black and white checkered lip pattern; belly colour including uncolored or yellow; dorsum smooth or with warts and with or without a mid-dorsal line; upper half of the iris colour red, gold or silver; underside of throat with a mottled grey pattern or many isolated small grey points; lower half of the iris colour silver or maroon; the facial mask (following 21) having none or scattered black blotches (Z1), dark face mask reaching the tympanum (Z2) and dark face mask reaching beyond the tympanum (Z3); the presence or absence of a seat patch (see Figure S2). The colouration of the iris, belly, and thighs was classified into categories based on comparisons to 160 colour shades representing 11 standard colours ranging from white to black on the web based X11 colour codes chart.

\section{Molecular analysis}

DNA from buccal swabs was isolated [22]. Swabs were placed in $1.5 \mathrm{~mL}$ microcentrifuge tubes and $600 \mu \mathrm{L}$ of $50 \mathrm{mM} \mathrm{NaOH}$ was added. The tube was vortexed for $5 \mathrm{~min}$ and then heated at $95^{\circ} \mathrm{C}$ for $10 \mathrm{~min}$. Finally, $120 \mu \mathrm{L}$ of $1 \mathrm{M}$ Tris ( $\mathrm{pH}$ 8.0) was added to the tube, vortexed and the swab removed and discarded. DNA from tissue samples was isolated using Qiagen DNeasy Blood and Tissue Kits following the procedure for animal tissue. Mitochondrial sequence data was collected from fragments of two genes, the cytochrome $c$ oxidase I (COI) and 16S ribosomal RNA (16S). The COI marker was amplified by polymerase chain reaction (PCR) using the primer pairs CO1f (5'CCT GCA GGA GGA GGA GAY CC-3') and COla (5'-AGT ATA AGC GTC TGG GTA GTC-3') and the 16 S marker was amplified using 16sar (5'-CGC CTG TTT ATC AAA AAC AT-3') and 16sbr (5'-CCG GTC TGA ACT CAG ATC ACG T-3') [23]. The $50 \mu \mathrm{L}$ PCR contained $10 \mu \mathrm{L}$ of DNA template, $5.0 \mu \mathrm{L} 10 \times$ PCR buffer, $0.2 \mu \mathrm{m}$ of each primer, $0.2 \mathrm{mM}$ of each dNTP, and 1 unit of Taq DNA polymerase. The PCR products were unidirectionally sequenced using $\mathrm{ABI} 3130$ sequencer. All molecular sequence analysis was done within MEGA 6.0 [24]. Sequences were aligned in ClustalW using the default parameters [25]. For each gene, phylogenies were inferred separately using maximum likelihood approaches. The HKY+I model [26] and the T92+I model [27] were selected as the best fit to the COI and $16 \mathrm{~S}$ data respectively using Bayesian Information Criterion [28]. Clade support was assessed by non-parametric bootstrapping involving 1000 pseudoreplicates. The COI and $16 \mathrm{~S}$ trees were rooted using Hyla intermedia (Hylidae, gb:FJ226788.1) and Phyllobates lugubris (Dendrobatidae, gb:FJ784587.1) respectively. The mean molecular distance between clades was accessed by averaging the number of base substitutions per site from all sequence pairs between groups using the K2 model [29] and standard error estimates were obtained by a bootstrap procedure involving 1000 pseudo-replicates.

\section{Morphometric analysis}

A linear discriminant analysis was conducted to determine if the morphometric measurements and phenotypic patterns of specimens would support the species identified by the molecular analysis. We used the clade classification from the maximum likelihood analysis as a grouping factor, excluding specimens without molecular data. Independent analyses were performed on categorical phenotypic characters (Table S2) and continuous morphological measurements (Table S2), to evaluate their propensity for species delineation independently. Multivariate normality was assessed visually with a Q-Q plot based on the squared Mahalanobis distance. The morphological measurements were log transformed and the categorical phenotypic variables were entered as dummy variables ( 0 or 1$)$. All morphometric analyses were performed in R using the package MASS (lda; linear discriminant analysis) [30, 31].

\section{Delineation of candidate species}

First, we delineated well-supported clades and then attempted to identify them by searching GenBank for all corresponding $16 \mathrm{~S}$ and COI marker sequences identified as Craugastor. No prior published Craugastor sequences had enough similarity to provide clear identifications using COI, and these results were excluded. Next, we examined whether these clades could be distinguished from each other using the morphometric or phenotypic data. Finally, we evaluated the Automatic Barcode Gap Discovery (ABGD) algorithm's ability to delineate species within the unclassified specimens [11]. A genetic distance matrix was built in MEGA6 with model and parameter values similar to the phylogenetic analysis described above and used as input for the ABGD web interface. Prior maximum intraspecific divergences thresholds were set to test 20 values ranging from $0.1 \%$ and $15 \%$.

\section{Results}

Within this study, 79 (41\%) and 52 (27\%) Craugastor tissue samples were successfully amplified for the $16 \mathrm{~S}$ and COI mitochondrial gene markers respectively. The final alignment of $16 \mathrm{~S}$ sequences contained no gaps and consisted of 436 characters with 155 variable sites. The final COI sequence alignment consisted of 611 characters with 140 variable sites and the translated protein contained 203 amino acids with no internal stop codons. The maximum likelihood phylogenetic reconstruction for $16 \mathrm{~S}$ and $\mathrm{COI}$ identified four and three well supported reciprocal monophyletic clades respectively (Figure 2). Clades A, B and $\mathrm{D}$ were distinguished with both genetic markers, however, clade $\mathrm{C}$ was present only with $16 \mathrm{~S}$. Only clade $\mathrm{C}$ aligned with sequences extracted from GenBank (Figure S3) and was identified as C. laticeps. The minimum mean sequence divergence between clades was $13.3 \pm$ $1.6 \%$ and $4.6 \pm 1.0 \%$ for COI and $16 \mathrm{~S}$ respectively (Table 2 ).

The linear discriminant analysis (LDA) on continuous morphometric measurements with clades as a grouping factor included $45(23 \%)$ specimens and extracted three discriminant axes explaining $58 \%, 34 \%$ and $8 \%$ of the variation respectively (Table 3 ). Snout length and head width were the major discriminating characteristics on the first axis, head length on the second axis and snout vent length on the third axis. The overall classification efficiency of the model, calculated as the average prediction for all samples, was $0.80 \pm 0.18$. There was substantial overlap in the measured variables and no diagnostic features were isolated (Figure 3A). The LDA on discrete phenotypic characters with clades as a grouping factor included 38 (20\%) specimens. Lower iris colour data needed to be excluded from the LDA analysis as they perfectly separated clade D, composed of silver, from clades A, B and C, composed of maroon. The LDA on phenotypic patterns with the remaining characters extracted three linear discriminant axes explaining 
Citation: D'Souza ML, Witt JDS, Kolby J, Clegg J, Jankowski A, et al. (2016) Having an Eye for Species Identification: Iris Colouration Is Diagnostic In Highly Variable Leaf Litter (Craugastor: Craugastoridae) Frogs. Entomol Ornithol Herpetol 5: 178. doi:10.4172/2161-0983.1000178

Page 4 of 7

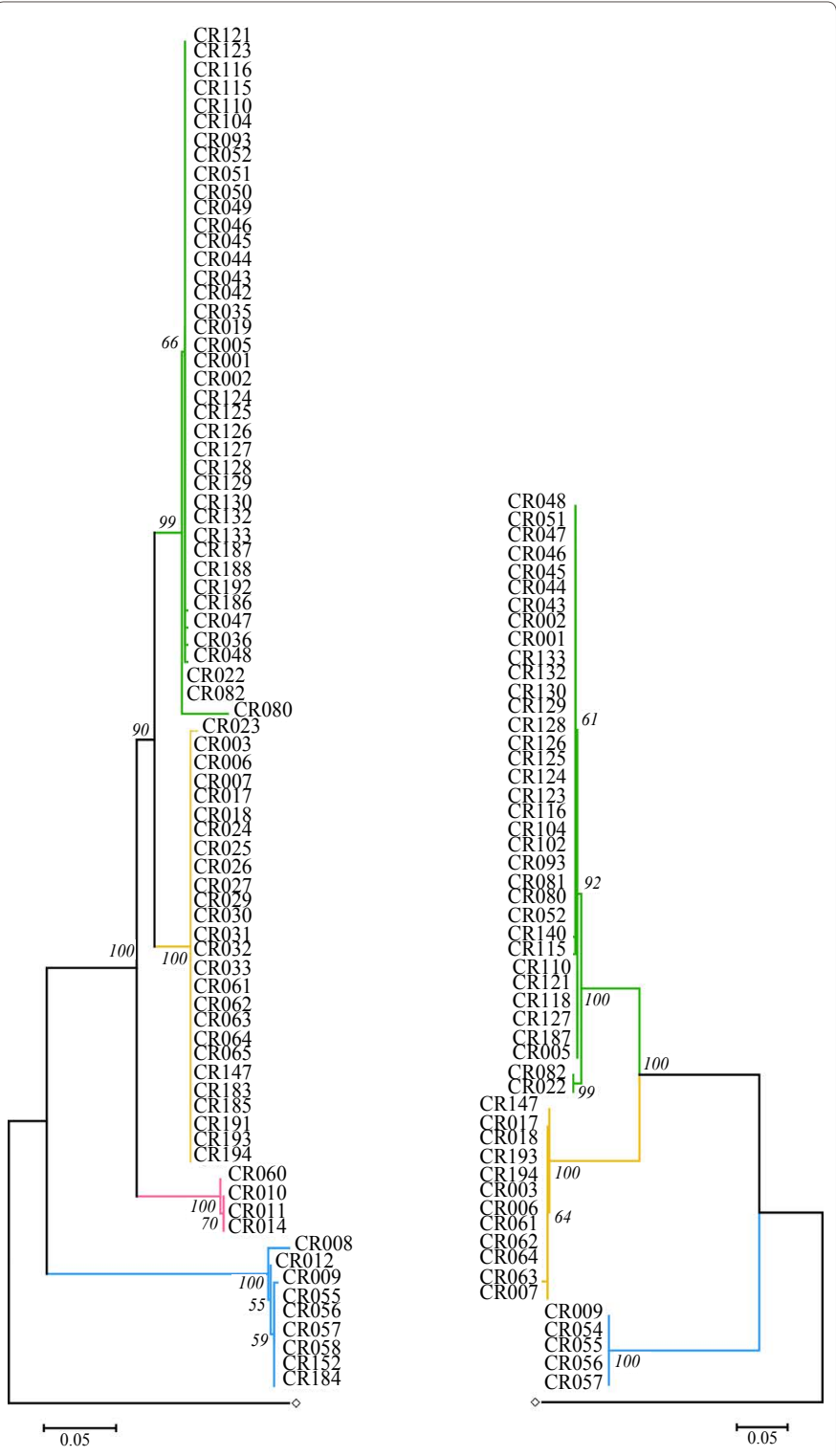

Figure 2: Maximum likelihood phylogeny of Craugastor in Cusuco National Park inferred from $16 \mathrm{~S}$ (left) and COI (right) gene fragments representing 79 and 52 specimens respectively. The four clades A, B, C and D are highlighted in green, gold, pink and blue respectively. $\mathrm{COI}$ and $16 \mathrm{~S}$ trees rooted $(\diamond)$ using Hyla intermedia (Hylidae, gb:FJ226788.1) and Phyllobates lugubris (Dendrobatidae, gb:FJ784587.1) respectively. Tree is drawn to scale with branch lengths in units of number of base substitutions per site and with 1000 bootstrap replicate values indicated.

$59 \%, 29 \%$ and $12 \%$ of the variation respectively (Table 4). Upper iris colouration, including gold, silver and red, were major discriminating characteristics on all three axes. The overall classification efficiency of the model, calculated as the average prediction for all samples, was 0.84 \pm 0.35 . The LDA on phenotypic characters resulted in distinct clusters that more clearly separated the four phylogenetic clades (Figure 3B). There were only two individuals that did not cluster appropriately based on upper iris colouration (CR60 and CR115).

Overall, the combination of lower and upper iris colouration was found to be a strong diagnostic character for species identification. Clade A was identified as Craugastor rostralis, characterized by a gold upper half and a maroon lower half of the iris; clade B was identified as
Craugastor chac with a red upper half of the iris and a maroon lower half of the iris; clade $\mathrm{C}$ was identified as Craugastor laticeps with a silver upper half and a lower maroon half of the iris; clade D was identified as

\begin{tabular}{|c|c|c|c|c|}
\hline & A & B & C & D \\
\hline A & & $0.046 \pm 0.010$ & $0.085 \pm 0.014$ & $0.200 \pm 0.023$ \\
\hline B & $0.133 \pm 0.016$ & & $0.091 \pm 0.015$ & $0.194 \pm 0.023$ \\
\hline C & n/a & n/a & & $0.222 \pm 0.025$ \\
\hline D & $0.192 \pm 0.018$ & $0.210 \pm 0.019$ & n/a & \\
\hline
\end{tabular}

Table 2: Mean sequence divergence \pm standard error between clades $A, B, C$ and $\mathrm{D}$ for $16 \mathrm{~S}$ (top) and COI (bottom) gene markers.

\begin{tabular}{|c|c|c|c|}
\hline Parameter name & LD1 $(58 \%)$ & LD2 $(34 \%)$ & LD3 $(8 \%)$ \\
\hline Snout length & -12.84 & -19.02 & -5.549 \\
\hline Head width & -11.98 & 17.84 & 3.136 \\
\hline Eye/tympanum & -1.836 & -18.02 & -5.096 \\
\hline Foot length & -1.443 & 0.909 & -7.143 \\
\hline Tympanum & 0.283 & -16.07 & -9.351 \\
\hline Hind leg & 0.902 & 1.977 & -4.063 \\
\hline Head length & 1.479 & 33.80 & 6.681 \\
\hline Snout vent length & 6.615 & -8.158 & 16.98 \\
\hline Weight & 6.869 & -0.518 & -1.492 \\
\hline
\end{tabular}

The percentage of variance in the dataset explained by respective axes is mentioned in brackets

Table 3: Loadings of three linear discriminant analysis axes for 9 morphological measurements of 45 Craugastor individuals.

A
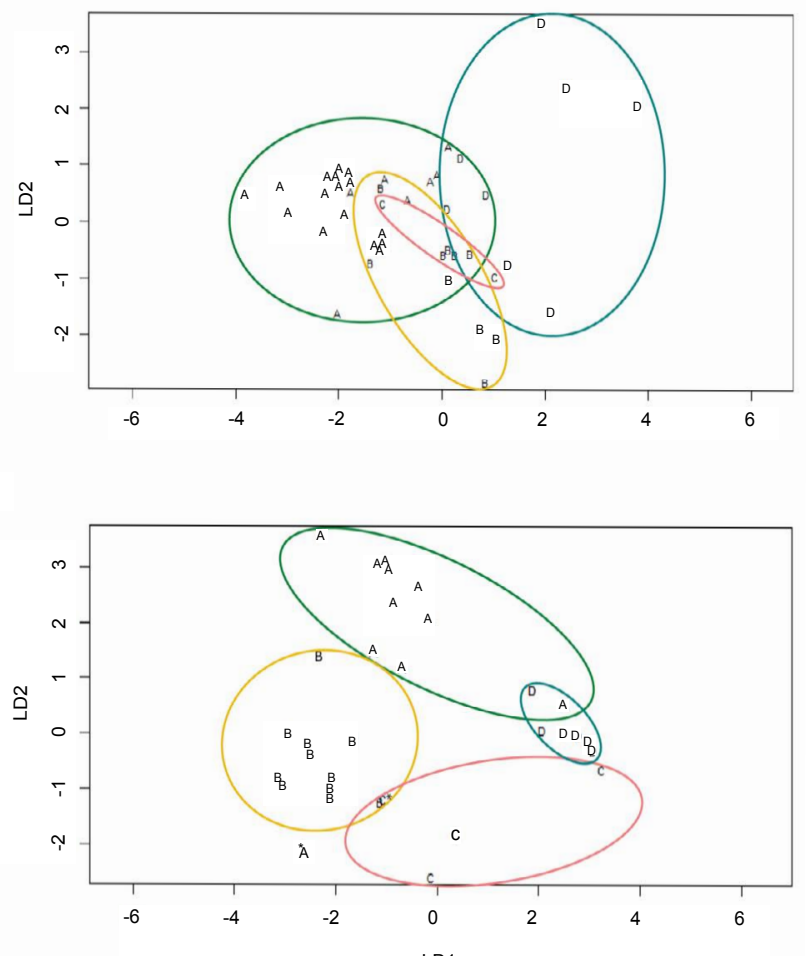

LD1

Figure 3: Biplot of first two axes of the linear discriminant analysis on morphological $(A)$ and phenotypic $(B)$ data, including 45 and 38 specimens respectively, with molecularly identified species as categories. Coloured circles group the clades: clade A highlighted in green, clade B highlighted in gold, clade $\mathrm{C}$ highlighted in pink and clade $\mathrm{D}$ highlighted in blue. Two outlier specimens indicated by the asterisks. 


\begin{tabular}{|c|c|c|c|}
\hline Parameter name & LD1 (59\%) & LD2 (29\%) & LD3 (12\%) \\
\hline Upper eye red & -0.547 & -0.683 & 0.538 \\
\hline Throat pointed & -0.369 & 0.076 & -0.018 \\
\hline Thighs red & -0.368 & 0.557 & -0.048 \\
\hline Face mask z2 & -0.357 & 0.433 & 0.127 \\
\hline Seat patch & -0.250 & 0.390 & 0.032 \\
\hline Dorsal ridge & -0.190 & 0.212 & 0.110 \\
\hline Thighs uncoloured & -0.137 & -0.467 & -0.066 \\
\hline Face mask z3 & 0.030 & -0.103 & -0.104 \\
\hline Thighs orange & 0.142 & 0.029 & -0.197 \\
\hline Belly yellow & 0.239 & -0.355 & 0.284 \\
\hline Face mask z1 & 0.282 & -0.269 & 0.004 \\
\hline Throat mottled & 0.297 & -0.064 & -0.012 \\
\hline Warthy skin & 0.345 & -0.070 & 0.782 \\
\hline Upper eye silver & 0.400 & -0.494 & -1.583 \\
\hline Thighs yellow & 0.505 & -0.236 & 0.538 \\
\hline Upper eye gold & 0.666 & 1.640 & 0.312 \\
\hline Lips checkered & 1.949 & -1.006 & -0.845 \\
\hline
\end{tabular}

The percentage of variance in the dataset explained by respective axes is mentioned in brackets.

Table 4: Loadings of three linear discriminant analysis axes for 18 phenotypic characteristics recorded from photographs of 38 Craugastor individuals.

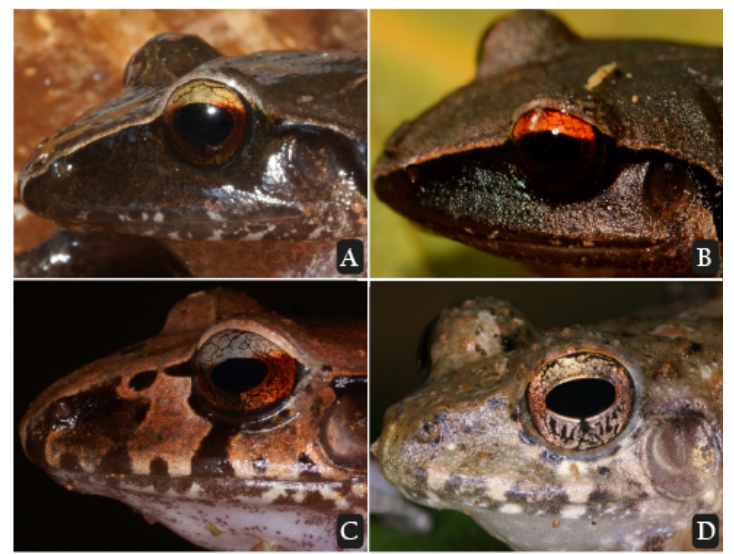

Figure 4: Images indicating diagnostic iris colour for molecular clades A, B, C and $\mathrm{D}$ representing Craugastor rostralis, Craugastor chac, Craugastor laticeps and Craugastor cf. charadra respectively. C. rostralis characterized by a gold upper half and a maroon lower half of the iris; C. chac characterized by a red upper half and a maroon lower half of the iris; $\mathrm{C}$. laticeps characterized by a silver upper half and a lower maroon half of the iris; C. cf. charadra characterized by a gold upper half and a silver lower half of the iris.

Craugastor cf. charadra and was characterized by a gold upper half and a silver lower half of the iris (Figure 4).

The Automatic Barcode Gap Discovery (ABGD) algorithm was applied to the 79 (41\%) and $52(27 \%)$ Craugastor specimens that were successfully sequences for $16 \mathrm{~S}$ and COI mitochondrial gene markers respectively. A maximum intraspecific sequence threshold of $4.15 \%$ at $16 \mathrm{~S}$ and $13.0 \%$ at COI implied 4 and 3 clades respectively. The clades or putative species generated by the ABGD algorithm were consistent with the maximum likelihood phylogenetic reconstruction and iris colouration diagnosis (Figure 2 and Table 2) further supporting the presence of four distinct species.

\section{Discussion}

The phylogenetic species concept distinguishes a species as the smallest biological unit that is monophyletic and supported by unique apomorphic characters [32]. On this basis, we clearly delineated four sympatric species of Craugastor, which were also independently recognized using a diagnostic phenotypic character and a sequence similarity-based approach. The 16S and COI phylogenetic analyses distinguished three well supported monophyletic clades identified as C. rostralis, C. chac, and C. cf. charadra. A fourth species, C. laticeps, was differentiated using the $16 \mathrm{~S}$ marker, but poorer amplification success left it undetected with COI. The COI primer sites are known to be problematic in amphibians, and resulted in lower success rates than might be expected from other taxa [33]. As previously demonstrated, and further supported in this study, $16 \mathrm{~S}$ is an important complementary marker to COI in amphibian studies $[7,12]$.

All four monophyletic clades were reliably distinguished based on a combination of upper and lower iris colour while alive. Iris colouration in frogs has been demonstrated to have a clear association with ecology [34]. A horizontally contrasted iris pattern, differing between the upper and lower iris, and a large dark tympanic patch are a typical eye structure for frogs inhabiting leaf litter [35]. It is hypothesized that iris colouration could affect vision, function as a predator deterrent or be important as a mate recognition signal [36]. The stability of iris colouration within the four Craugastor species in this study may point towards individual or mate recognition as a plausible hypothesis, particularly considering the otherwise highly variable morphology. Iris colouration is a common characteristic used in amphibian field identification guides due to its restricted variability, especially when used in conjunction with species range data. It was particularly useful in differentiating the two highly variable sympatric species, $C$. rostralis and C. chac, which are both typically light brown with darker markings on the hind legs. We have identified a diagnostic phenotypic character that will be crucial for the reliable differentiation of species in the field. A further three species have been reported from Cusuco National Park including C. milesi [37], C. laevissimus and C. coffeus (Operation Wallacea Ltd. unpublished data). These species are more readily identifiable than the cryptic species examined in this study, but have yet to be confirmed using molecular analysis.

The Automatic Barcode Gap Discovery (ABGD) algorithm, the sequence similarity-based tool evaluated in this study, successfully identified groups concordant with the four well supported monophyletic clades of the maximum likelihood phylogenetic analysis and matched the diagnostic phenotypic character of iris colouration between clades. The evaluation of various threshold values employed in the ABGD algorithm, obtained from the sequence data themselves, further tested and provided support for previously identified sequence threshold values for amphibian species in other studies [38,39]. The results from this study demonstrate that the ABGD algorithm is highly applicable in the diagnosis of phylogenetic species and can be an important tool in the identification of cryptic species within amphibian groups. Furthermore, we demonstrate how mitochondrial genetic data, in conjunction with phenotypic character analyses can provide a strong framework for reliable field identification as well as the evaluation of DNA sequence similarity-based tools currently available for the assessment of species boundaries within amphibian datasets.

\section{Author Contributions}

Michelle L. D'Souza and Merlijn Jocque designed the study; Michelle L. D'Souza completed the sequence analyses; Michelle L. D'Souza, Merlijn Jocque and Jonathan Witt led the data analysis. All authors discussed the results and contributed to the manuscript, which was written by Michelle L. D'Souza and Merlijn Jocque. Neil Reid and Jonathan Witt provided helpful revisions of the original draft. 
Citation: D'Souza ML, Witt JDS, Kolby J, Clegg J, Jankowski A, et al. (2016) Having an Eye for Species Identification: Iris Colouration Is Diagnostic In Highly Variable Leaf Litter (Craugastor: Craugastoridae) Frogs. Entomol Ornithol Herpetol 5: 178. doi:10.4172/2161-0983.1000178

Page 6 of 7

\section{Acknowledgment}

We would like to thank the local people living around Cusuco National Park for their guidance on numerous forest excursions. Also, thanks go to the Instituto Nacional de Conservacin Forestal (ICF) for help with research and export permits. Furthermore we would like to thank all volunteers and students of Operation Wallacea Ltd. that helped during surveys. This study was supported by an NSERC discovery grant (327509) to Jonathan Witt.

\section{Data Accessibility}

DNA sequences: Genbank

Morphological data: online Supporting Information

\section{References}

1. Honeycutt RL, Hillis DM, Bickham WK (2010) Biodiversity discovery and its importance to conservation. Molecular Approaches in Natural Resource Conservation and Management, Cambridge University Press, New York pp: $1-34$.

2. Padial JM, Miralles A, De la Riva I, Vences M (2010) The integrative future of taxonomy. Frontiers in Zoology 7: 16.

3. Schlick-Steiner BC, Steiner FM, Seifert B, Stauffer C, Christian E, et al. (2010) Integrative taxonomy: a multisource approach to exploring biodiversity. Annual Rev Entomology 55: 421-438.

4. Thompson KA, Newmaster SG (2014) Molecular taxonomic tools provide more accurate estimates of species richness at less cost than traditional morphology-based taxonomic practices in a vegetation survey. Biodiversity and Conservation 23: 1411-1424.

5. Stuart BL, Inger RF, Voris HK (2006) High level of cryptic species diversity revealed by sympatric lineages of Southeast Asian forest frogs. Biology Letters 2: 470-474.

6. Funk WC, Caminer M, Ron SR (2011) High levels of cryptic species diversity uncovered in Amazonian frogs. Proc R Soc B 279: 1806-1814.

7. Crawford AJ, Lips KR, Bermingham E (2010) Epidemic disease decimates amphibian abundance, species diversity, and evolutionary history in the highlands of central Panama. Proc Natl Acad Sci 107: 13777-13782.

8. Munch K, Boomsma W, Huelsenbeck JP, Willerslev E, Nielsen R (2008) Statistical assignment of DNA sequences using Bayesian phylogenetics. Systematic Biology 57: 750-757.

9. Fujisawa T, Barraclough TG (2013) Delimiting species using single-locus data and the generalized mixed yule coalescent approach: a revised method and evaluation on simulated data sets. Systematic Biology 62: 707-724.

10. Ratnasingham S, Hebert PD (2013) A DNA-based registry for all anima species: the barcode index number (BIN) system. Plos one 8: e66213.

11. Puillandre N, Lambert A, Brouillet S, Achaz G (2012) ABGD, Automatic Barcode Gap Discovery for primary species delimitation. Molecular Ecology 21: 1864-1877.

12. Paz A, Crawford AJ (2012) Molecular-based rapid inventories of sympatric diversity: A comparison of DNA barcode clustering methods applied to geography-based vs clade-based sampling of amphibians. Journal of Biosciences 37: 887-896.

13. Crawford AJ, Cruz C, Griffith E, Ross H, Ibáñez R, et al. (2013) DNA barcoding applied to ex situ tropical amphibian conservation programme reveals cryptic diversity in captive populations. Molecular Ecology Resources 13: 1005-1018.

14. AmphibiaWeb: Information on amphibian biology and conservation (2015) Berkeley, California.

15. Savage JM, Emerson SB (1970) Central American frogs allied to Eleutherodactylus bransfordii (Cope): a problem of polymorphism. Copeia 623-644.

16. Crawford AJ, Smith EN (2005) Cenozoic biogeography and evolution in directdeveloping frogs of Central America (Leptodactylidae: Eleutherodactylus) as inferred from a phylogenetic analysis of nuclear and mitochondrial genes. Mol Phylogenet Evol 35: 536-555.

17. Kolby JE, Padgett-Flohr GE, Field R (2010) Amphibian chytrid fungus Batrachochytrium dendrobatidis in Cusuco National Park, Honduras. Dis Aquat Org 92: 245-251.
18. Le Saout S, Hoffmann M, Shi Y, Hughes A, Bernard C, et al. (2013) Protected areas and effective biodiversity conservation. Science 342: 803-805.

19. Duellman WE (1970) The Hylid Frogs of Middle America. Lawrence: University of Kansas, USA.

20. Lynch JD, Duellman WE (1980) The eleutherodactylus of the amazonian slopes of the ecuadorian andes (Anura: Leptodactylidae). Lawrence: University of Kansas, USA.

21. Savage JM (1987) Systematics and distribution of the Mexican and Central American rainfrogs of the Eleutherodactylus gollmeri group (Amphibia: Leptodactylidae). Fieldiana Zoo 33: 1-57.

22. Walker AH, Najarian D, White DL, Jaffe JF, Kanetsky PA, et al. (1999) Collection of genomic DNA by buccal swabs for polymerase chain reactionbased biomarker assays. Environ Health Perspect 107: 517-520.

23. Palumbi S, Martin A, Romano S, McMillan WO, Stice L, et al. (1991) The Simple Fool's Guide to PCR.

24. Tamura K, Stecher G, Peterson D, Filipski A, Kumar S (2013) MEGA6: molecular evolutionary genetics analysis version 6.0. Mol Biol Evol 30: 27252729

25. Thompson JD, Higgins DG, Gibson TJ (1994) CLUSTAL W: improving the sensitivity of progressive multiple sequence alignment through sequence weighting, position-specific gap penalties and weight matrix choice. Nucleic Acids Res 22: 4673-4680.

26. Hasegawa M, Kishino H, Yano TA (1985) Dating of human-ape splitting by a molecular clock of mitochondrial DNA. J Mol Evol 22: 160-174.

27. Tamura K (1992) Estimation of the number of nucleotide substitutions when there are strong transition-transversion and $\mathrm{G}+\mathrm{C}$ content biases. Mol Biol Evol 9: 678-687.

28. Schwarz G (1978) Estimating the dimension of a model. The annals of statistics 6: 461-464.

29. Kimura M (1980) A simple method for estimating evolutionary rates of base substitutions through comparative studies of nucleotide sequences. Journal of molecular evolution 16: 111-120.

30. R Core Team (2013) R: A language and environment for statistical computing R Foundation for Statistical Computing, Vienna, Austria.

31. Venables WN, Ripley BD (2002) Modern Applied Statistics with S. (4th edn) Springer, New York.

32. Rosen DE (1978) Vicariant patterns and historical explanation in biogeography Syst Biol 27: 159-188

33. Vences M, Thomas M, Bonett RM, Vieites DR (2005) Deciphering amphibian diversity through DNA barcoding: chances and challenges. Philosophical transactions of the Royal Society of London B: Biological Sciences 360: 18591868.

34. Amat F, Wollenberg KC, Vences M (2013) Correlates of eye colour and pattern in mantellid frogs. Salamandra 49: 7-17.

35. Toledo LF, Haddad CF (2009) Colors and Some Morphological traits as defensive mechanisms in anurans. Int J Zool pp: 1-12.

36. Glaw F, Vences M (1997) Anuran eye colouration: definitions, variation taxonomic implications and possible functions. Herpetologia Bonnensis pp: 125-138.

37. Kolby JE, McCranie JR (2009) Discovery of a surviving population of the montane streamside frog Craugastor milesi (Schmidt). Herpetological Review 40: 282

38. Vences $M$, Thomas $M$, van der Meijden A Chiari $Y$, Vieites DR (2005) Comparative performance of the 16S rRNA gene in DNA barcoding of amphibians. Front Zool 2: 1-12.

39. Fouquet A, Gilles A, Vences M, Marty C, Blanc M, et al. (2007) Underestimation of species richness in neotropical frogs revealed by mtDNA analyses. PLoS ONE 2: e1109.

40. Duméril A (1853) Mémoire sur les batraciens anoures, de la famille des Hylaeformes ou Rainettes: comprenant la description d'un genre nouveau et de onze espèces nouvelles. Imprimerie de J. Martinet.

41. Werner F (1896) Beiträge zur Kenntniss der Reptilien und Batrachier 
Citation: D'Souza ML, Witt JDS, Kolby J, Clegg J, Jankowski A, et al. (2016) Having an Eye for Species Identification: Iris Colouration Is Diagnostic In Highly Variable Leaf Litter (Craugastor: Craugastoridae) Frogs. Entomol Ornithol Herpetol 5: 178. doi:10.4172/2161-0983.1000178

von Centralamerika und Chile, sowie einiger seltenerer Schlangenarten. Verhandlungen des Zoologisch-Botanischen Vereins in Wien 46: 344-365.

42. Campbell JA, Savage JM (2000) Taxonomic reconsideration of Middle American frogs of the Eleutherodactylus rugulosus group (Anura: Leptodactylidae): a reconnaissance of subtle nuances among frogs. Herpetol Monogr 14: 186-292.
43. McCraine JR, Köhler G (1999) A new species of rainfrog of the Eleutherodactylus gollmeri group from western Honduras (Amphibian, Anura, Leptodactylidae). Senckenbergiana Biol 79: 83-88.

44. Schmidt KP (1933) New reptiles and amphibians from Honduras. Zoological Series 20: 15-22.
Citation: D'Souza ML, Witt JDS, Kolby J, Clegg J, Jankowski A, et al. (2016) Having an Eye for Species Identification: Iris Colouration Is Diagnostic In Highly Variable Leaf Litter (Craugastor: Craugastoridae) Frogs. Entomol Ornithol Herpetol 5: 178. doi:10.4172/2161-0983.1000178
OMICS International: Open Access Publication Benefits \& Features

Unique features:

- Increased global visibility of articles through worldwide distribution and indexing

Showcasing recent research output in a timely and updated manner

Special issues on the current trends of scientific research

Special features:

- $700+$ Open Access Journals

$50,000+$ Editorial team

Rapid review process

Quality and quick editorial, review and publication processing

Indexing at major indexing services

- Sharing Option: Social Networking Enabled

- Authors, Reviewers and Editors rewarded with online Scientific Credits

- Better discount for your subsequent articles

Submit your manuscript at: www.omicsonline.org/submission 